\title{
Using Mapping of Service Delivery Sites to Increase Contraceptive Availability in Kinshasa, Democratic Republic of the Congo
}

The Democratic Republic of the Congo (DRC) represents one of the greatest demographic challenges of our time. With a natural increase of $2.8 \%$ a year, the Sub-Saharan African country's population of more than 69 million inhabitants will double by 2037. ${ }^{1}$ The problems of rapid population growth are nowhere more evident than in Kinshasa, the DRC's capital: The province of Kinshasa has an estimated current population of approximately 10 million living in an expanse of 3,847 square miles. ${ }^{2}$

On the Family Planning Program Effort Index, the assessment of the strength of family planning programs that was last conducted in 2009, the DRC ranked in the bottom $10 \%$ of countries worldwide. ${ }^{3}$ The DRC's National Program for Reproductive Health-the government office charged with coordinating and overseeing family planning-has lacked the human and financial resources to effectively carry out its role. As of 2011, at least 10 local and international nongovernmental organizations (NGOs) were providing some type of family planning service delivery in Kinshasa; however, each tended to work in isolation. Although these groups have worked diligently to attain their own project objectives, there was no coordinated effort to collectively increase contraceptive prevalence in Kinshasa.

This special report presents a case study of a promising model for increasing contraceptive availability in Kinshasa, which could be replicated in other large cities in the DRC and elsewhere in the region.

\section{CONTEXT}

The DRC is the third largest country in Sub-Saharan Africa and the largest francophone African country. ${ }^{4}$ Similar to other francophone countries in West and Central Africa, the DRC has high fertility rates, low modern contraceptive prevalence rates and high unmet need for family planning. 5 . 6 The fragile progress that the country made in the 1980s (when it was known as Zaire) in terms of family planning was quickly reversed by political unrest, governmental mismanagement and general turmoil in all aspects of daily life from the early 1990s to the early 2000s. As of 2010 , contraceptive prevalence (the proportion of married women aged 15-49 using a modern contraceptive method) was $5 \%$ for the country overall and 13\% for Kinshasa. ${ }^{5}$ Unmet need-the proportion of married women aged 1549 who do not want a pregnancy in the next 24 months (or ever), yet are not using a contraceptive method-was $24 \%$ in both Kinshasa and the DRC as a whole. .,6 $^{2}$

The prospects for curbing rapid population growth are daunting. The government has allocated meager resources for health services overall (less than US $\$ 4.22$ per annum per person), much less for family planning. ${ }^{7}$ Until recently, there has been little political will for investing in family planning; the National Health Development Plan does not explicitly mention family planning, although it does cite reproductive health. ${ }^{8}$ Consequently, there has been no line item in the national budget to support family planning. Although international donors are keenly aware of the enormous needs for family planning in the DRC, they have been apprehensive of investing there because of governance issues at all levels, political instability (especially in the east), lack of public health infrastructure and uncertainty regarding attainable results.

Increasing contraceptive prevalence requires an adequate supply of services, on the one hand, and an adequate demand for those services, on the other hand. As of 2011, when the work presented in this report began, little was known about either supply or demand in the context of Kinshasa. Thus, an important first step was to assess supply by identifying all health facilities and pharmacies in Kinshasa that offered at least one contraceptive method. A short survey of family planning sites was conducted in early 2012, which provided detailed information on the number and geographic location of sites, as well as their key attributes (e.g., type of contraceptives available, number of staff with family planning training). And although the content of this short survey of family planning sites was very basic, the utilization of the results merits special attention, as it led to three follow-up actions: a state-of-theart mapping of all family planning sites on a interactive Google Earth map, to assess coverage and identify underserved areas throughout the city; the creation of the Kinshasa Family Planning Coalition, which consists of the 10 organizations involved in family planning service delivery in Kinshasa and four international donor agencies; and heightened interest of international donors in investing in family planning in Kinshasa because this evidence base was available to guide such work.

Mapping of health facilities is by no means new. McLafferty presents a useful overview of geographic information systems (GIS) and related spatial analytic techniques that provide a set of tools for describing and understanding the changing spatial organization of health care, for examining its relationship to health outcomes and access, and for exploring how health care delivery can be improved. ${ }^{9}$ However, little such research has been conducted in resourcepoor settings. Tanser and Wilkinson used GIS to increase

\section{By Jane T. Bertrand, Patrick Kayembe, Nelly Dikamba, Eric Mafuta, Julie Hernandez, Jacqueline Hellen and Arsene Binanga}

Jane T. Bertrand is professor and, at the time of this study, Jacqueline Hellen was a research assistantboth with the School of Public Health and Tropical Medicine, Tulane University, New

Orleans, LA, USA.

Patrick Kayembe is professor, Nelly Dikamba is professor, and Eric Mafuta is assistant professor-all with the Kinshasa School of Public

Health, Kinshasa, Democratic Republic of the Congo (DRC). Julie Hernandez is research assistant professor, Payson Center, Tulane University. Arsene Binanga is Tulane's Director of Family Planning Projects in the DRC. 
accessibility of tuberculosis treatment in a community in South Africa by identifying areas with lower access to the district hospital and village health clinics, and by assigning community health workers and volunteers to these areas. ${ }^{10}$ Kazembe et al. identified geographical disparities in core population coverage indicators for Roll Back Malaria in Malawi. ${ }^{11}$ And Lozano-Fuentes et al. demonstrated the use of Google Earth to strengthen public health capacity and facilitate management of vector-borne diseases in resourcepoor environments. ${ }^{12}$ Given the potential value of GIS technology, it has been greatly underutilized, especially in relation to family planning.

This special report describes our survey of health facilities and pharmacies in Kinshasa, and the subsequent mapping exercise, the results of which are available in English at <http://familyplanning-drc.net/family-planning-sites-inkinshasa.php/>, or in French at <http://planificationfamiliale-rdc.net/centres-de-planification-familiale.php>.

\section{HEALTH FACILITY AND PHARMACY SURVEY}

The Kinshasa School of Public Health-in collaboration with the Tulane School of Public Health and Tropical Medicine-conducted a facility-based survey in Kinshasa between January and March 2012. The objectives were to identify, conduct a simple assessment and record the geographic location of all health facilities and major pharmacies in the city that sold contraceptive methods or distributed them free of charge. We included pharmacies as well as health facilities in the sample, given that $55 \%$ of married women using modern contraceptives in Kinshasa obtain their contraceptives from pharmacies. ${ }^{6}$ Institutional review board approval was obtained prior to the survey from both universities.

Health facilities (i.e., public or private hospitals, clinics, health centers and health posts) that offered contraceptives for sale or distributed them free of charge were identified by obtaining lists of sites supported by the key organizations working in family planning and by consulting the district medical officer (médecin chef de zone). To obtain the sample of major pharmacies, we took an exhaustive convenience sample of pharmacies most likely to provide contraceptives, which consisted of every pharmacy encountered in all 35 health zones of the city along major avenues and transport routes, near commercial centers and markets, and around hospitals and large clinics.

Interviewers visited each site and administered a short questionnaire to the person who was responsible for family planning services, to collect specific information about the site: type of facility (e.g., hospital, clinic), ownership (e.g., public or private), delivery of family planning services, ${ }^{*}$ volume of each contraceptive method in stock, number of staff members trained in family planning in the past three years, availability of an information system to track the quantity of contraceptives sold or distributed free of

*Respondents were asked, "Are family planning services offered in your facility?" or "Are family planning products, including condoms, sold in your pharmacy?"
TABLE 1. Percentage of health facilities offering family planning services, by three-star rating criteria, according to survey year, Kinshasa, Democratic Republic of the Congo

\begin{tabular}{ll|l} 
Criteria & $\begin{array}{l}2012 \\
(\mathrm{~N}=184)\end{array}$ & $\begin{array}{l}2013-2014 \\
(\mathrm{~N}=398)\end{array}$ \\
\hline All & 44.1 & 63.6 \\
$\geq 3$ contraceptive methods in stock & 59.7 & 73.2 \\
$\geq 1$ staff trained in family planning in past & & \\
$\quad$ 3 years & 53.4 & 88.9 \\
Basic information system & 67.1 & 82.6
\end{tabular}

charge and quantities of methods sold or distributed. In addition, interviewers took a geographic location reading of the site with an Etrex global positioning system (GPS) device using the system WGS 84.

On the basis of the survey data, we created a quality rating system for sites that awarded one star each for having at least three modern contraceptives in stock, at least one staff member trained in family planning in the past three years and an information system that tracks the quantity of contraceptives distributed. Thus, sites that met all the criteria were rated as "three-star sites."

\section{SURVEY FINDINGS}

The survey identified a total of 1,872 sites in Kinshasa, of which $12 \%$ were health facilities and $88 \%$ were pharmacies. Among health facilities, most hospitals were public (63\%), whereas two-thirds of clinics, health centers and health posts were private (i.e., for profit, nonprofit NGOs or religious). Two-thirds of pharmacies were for profit. Overall, $82 \%$ of sites reported offering family planning services (84\% of health facilities and $82 \%$ of pharmacies). Among those not offering family planning services, the primary reasons were religious convictions (29\%), lack of product (28\%), weak demand for contraceptives (20\%), policy of the site owner or manager $(7 \%)$ and lack of training $(7 \%)$.

The rest of the findings are for health centers only, because pharmacies were not included in the subsequent intervention. Of the 184 health facilities (23 hospitals, 151 health centers, eight clinics and two health posts) that reported delivering family planning services, $12 \%$ had no contraceptives in stock the day of the interview. Availability of specific methods on the day of the visit varied by type of facility. Of hospitals, $82 \%$ had in stock the injectable, $17 \%$ condoms, 59\% the IUD, $26 \%$ the pill and $31 \%$ the implant; of health centers, $76 \%$ had in stock the injectable, $40 \%$ condoms, $53 \%$ the pill and $41 \%$ the IUD. Implants were not widely available: Only $21 \%$ of facilities had the method in stock on the day of the visit.

At the time of the interview, $60 \%$ of health facilities had at least three contraceptive methods available, 53\% had at least one person trained in family planning in the past three years, and $67 \%$ had a functional information system that tracked monthly volume of each contraceptive distributed (Table 1). In total, $44 \%$ of the health facilities that reported providing family planning were deemed threestar sites. 


\section{MAPPING OF FAMILY PLANNING SITES}

Using the collected GPS coordinate data, we mapped all family planning sites in Kinshasa to illustrate their location and distribution throughout the city and to identify underserved areas. Two series of maps were generated. The first are static, thematic maps displaying the distribution of all facilities by level of family planning services offered. For these, we created a master database recording the geographic location (exact latitude and longitude coordinates) of all surveyed facilities, which we input in ArcGIS 10.0. We ran specific queries to create layers displaying all surveyed facilities, all surveyed facilities offering family planning services and the specific attributes of each facility (i.e., available contraceptives, trained staff and an information system). In addition, we created two interactive maps using Google Earth. These maps display all surveyed sites and three-star sites on a satellite imagery background that allows users to zoom in and out for a more accurate and user-friendly representation of the site location. For each site on the interactive maps, a clickable icon displays a dropdown box with the name, address and type of the health structure, as well as the number of staff with family planning training, the number of contraceptive methods available on the day of the visit and the presence of an information system to track contraceptive distribution (Figure 1). On both types of map, health facilities appear as large bull's-eyes, and pharmacies as smaller bull's-eyes.

Figure 2 is an example of one of the maps produced using the "multiple ring buffer" functionality of ArcGIS. The inner ring displays all areas within $500 \mathrm{~m}$ of a three-star site, and the outer ring displays areas within $1 \mathrm{~km}$ of a threestar site; overlapping rings were dissolved for clearer visual

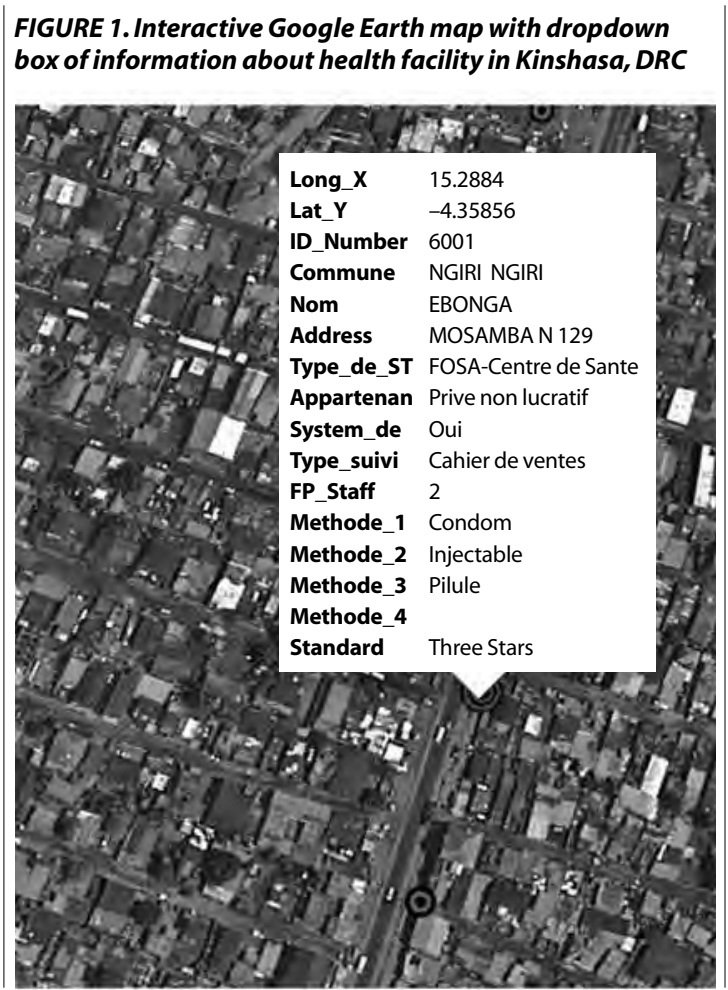

FIGURE 2. Static thematic map displaying distribution of health facilities in Kinshasa, DRC

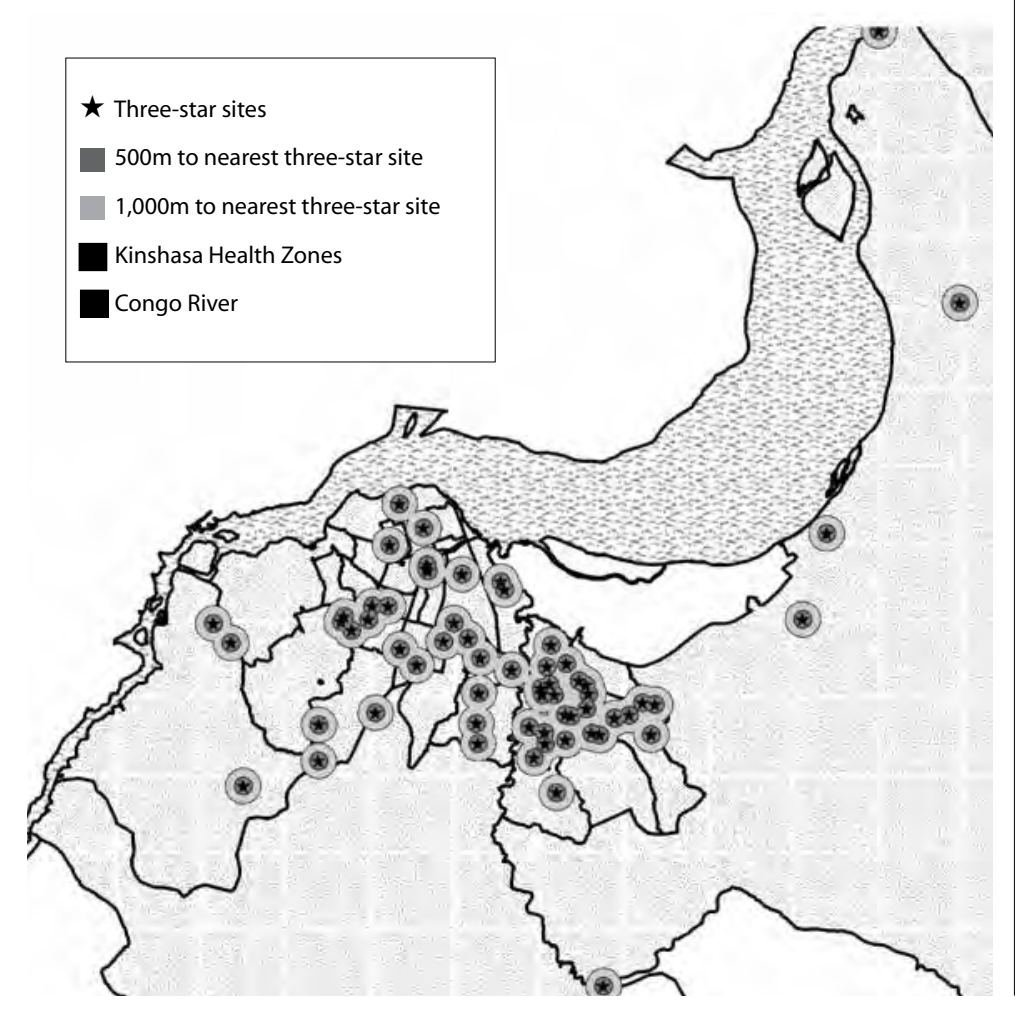

presentation. Distances of $500 \mathrm{~m}$ and $1 \mathrm{~km}$ were selected as reasonable walking distances to obtain contraceptive methods, given that Kinshasa residents tend to cover great distances on foot. Although clients are not limited to using health facilities in their own health zones, the maps show clear geographic disparities in access to family planning services. For example, the entire commune of Ngiri-Ngiri, located near Kinshasa's center, was within $1 \mathrm{~km}$ of a threestar site, whereas almost none of the less central commune of Binza Ozone had such accessibility (not shown).

\section{TRANSLATING FINDINGS INTO ACTION}

At the start of 2012, there was no centralized source of information on the family planning services delivered by different organizations throughout Kinshasa. In less than six months, however, we had collected data and produced maps that together provided one of the most detailed inventories of family planning service delivery available in any capital city in a francophone Sub-Saharan country, which in turn became the driver for a low-cost intervention with potential for replication in other cities of the DRC and beyond.

The intervention consisted of forming the Kinshasa Family Planning Coalition, convened under the auspices of the Ministry of Health and the National Program for Reproductive Health (PNSR). To initiate the formation of the coalition, we shared our data and interactive maps with the 10 organizations that supported family planning service delivery in government and private facilities in 
Kinshasa, as well as with key family planning donor agencies. The new information stimulated renewed interest in family planning. The inaugural meeting-held in December 2012-provided coalition members with a firsthand look at the interactive maps of family planning sites, which immediately placed each institution's efforts in the larger context of contraceptive access in Kinshasa as a whole.

One goal established by the coalition in its first meeting was to increase the proportion of health facilities offering family planning services that fulfilled the criteria to be considered a three-star site. As mentioned above, of the health facilities surveyed in 2012 that offered family planning services, $44 \%$ received a three-star rating. The coalition agreed to an ambitious goal of increasing this proportion to $80 \%$ by the end of 2013. In each subsequent quarterly meeting, the coalition focused on one criterion of the rating system to explore potential barriers that organizations would face in achieving the required results: contraceptive availability, trained personnel and information systems.

Between October 2013 and January 2014, we conducted a follow-up study with the same objectives as in 2012 of identifying all health facilities providing family planning services in Kinshasa, administering a short assessment and geocoding the location of each site; pharmacies were excluded from the follow-up survey. The results indicated an increase in the number of health facilities that reported providing family planning, from 184 in 2012 to 398 in 2013 (Table 1); of the sites surveyed in 2013-2014, 155 had also been surveyed in 2012. The proportion of health facilities with a three-star rating had increased to 64\% among all sites surveyed in 2013-2014. Although short of the $80 \%$ goal, the proportion achieved reflected a major improvement in access to and quality of family planning services in Kinshasa.

And although the primary value of the survey data and mapping was the motivation of service delivery organizations in Kinshasa to strengthen family planning programming in the health facilities they support, a secondary benefit has been the attention that these maps have drawn to the cause of family planning in the DRC. For donor agencies wishing to invest in evidence-based interventions, the data and mapping from this survey reflect a strategic and innovative approach to programming. In fact, several donors have started new family planning activities in Kinshasa that were influenced, at least partially, by this work.

\section{CONCLUSION}

This report reflects the value of collecting data and using interactive mapping technology to stimulate efforts to improve programming, even in one of the most challenging environments in the developing world. The model of establishing a baseline on contraceptive availability using open-source and user-friendly GIS technology, convening existing family planning partner organizations to collectively address the shortcomings of family planning sites they support and conducting a follow-up to monitor change, has strong potential for replication elsewhere.
GIS research emphasizes the geographic dimensions of access. However, health care decisions are strongly influenced by the type and quality of services available in the local area and the distance, time, cost and ease of traveling to reach those services. ${ }^{9}$ Traditional measures of access do not take into account the use of services in other communities, the choice not to use the nearest facility, redundant services in a community, the size of the population served (and the potential for overcrowded facilities) and variability in quality of care. ${ }^{13}$

One caveat from this study is the use of the three-star rating as a rough measure of quality. While programmatically useful because of its simplicity, it does not capture many elements considered essential to quality services (e.g., counseling, infection control, privacy).

An underlying assumption of this research was that access to contraception is a necessary (though not necessarily sufficient) condition for contraceptive use. But does proximity to family planning services increase contraceptive use? Entwisle et al. found a positive relationship between actual contraceptive availability and contraceptive use among women aged $25-44,{ }^{14}$ the age-group for which family planning services are most relevant. In their review article, Tsui and Ochoa concluded that proximity to contraceptive services does influence the use of contraceptives, although they cite caveats: Proximity to services does not necessarily equate to proximity to methods, nor does it necessarily enable current or potential contraceptive acceptors to easily obtain services related to the methods they are currently using. ${ }^{15}$ And using data from Morocco, Steele et al. found that the presence of a nearby public health center was associated with a higher proportion of women adopting a modern method after a birth and with lower rates of contraceptive discontinuation due to method failure (unintended pregnancy) among pill users, and that the presence of a pharmacy was associated with lower rates of contraceptive discontinuation among pill users because of side effects or health concerns. ${ }^{16}$ By contrast, other studies have found that quality of services outweighs proximity. In Egypt, quality of family planning services was more important than distance to the nearest service delivery site in predicting use of the IUD. ${ }^{17}$ In Guatemala, the majority of contraceptive users obtained their method from a location other than the nearest clinical facility offering family planning. ${ }^{18}$ Despite the mixed evidence on the relationship between service proximity and contraceptive use, in a location with fragile demand for family planning such as Kinshasa, availability of the product and quality of services are essential determinants of use.

The use of GIS and GPS technologies to map service delivery points is an underutilized strategy in family planning that merits implementation in other developing countries that have yet to achieve their family planning objectives. Access is only half of the "supply and demand" equation; however, improving access to contraceptives is an important step toward increasing method use in cities with great unmet need and limited progress. 


\section{REFERENCES}

1. Population Reference Bureau (PRB), World Population Data Sheet, Washington, DC: PRB, 2012.

2. Demographia, Demographia World Urban Areas, 10th ed., 2014, <http://www.demographia.com/db-worldua.pdf>, accessed Dec. 23 2012.

3. Ross J and Smith E, The Family Planning Effort Index: 1999, 2004 , and 2009, Washington, DC: Futures Group, 2010, <http://www.healthpolicyinitiative.com/Publications/Documents/1110_1_FP_Effort_ Index_1999_2004_2009_FINAL_05_08_10_acc.pdf>, accessed Dec. 23,2012

4. Central Intelligence Agency, The World Factbook, no date, <https:// www.cia.gov/library/publications/the-world-factbook/geos/cg.html>, accessed Oct. 5, 2011

5. Ministère du Plan, Institut National de la Statistique and United Nations Children's Fund (UNICEF), Democratic Republic of Congo Multiple Indicator Cluster Survey Preliminary Findings-MICS 2010, 2010, <http://www.childinfo.org/files/MICS-RDC_2010_Preliminary_Results_final_EN_imprime.pdf>, accessed Dec. 23, 2012

6. Ministère du Plan and Macro International, Enquête Démographique et de Santé, République Démocratique du Congo, 2007, Calverton, MD, USA: Ministère du Plan and Macro International, 2008.

7. Ministère de la Santé Publique, Secrétariat Général à la Santé Direction d'Études et Planification, Costing et planification de ressources des services de santé dans le cadre de la mise en ouuvre de la stratégie de renforcement du système de santé, Kinshasa, Democratic Republic of Congo: Ministère de la Santé Publique, Secrétariat Général à la Santé Direction d'Études et Planification, 2008.

8. Ministère de la Santé Publique, Secretariat Général, Plan national de développement sanitaire PNDS 2011-2015, Kinshasa, Democratic Republic of Congo: Ministère de la Santé Publique, Secrétariat Général, 2010.

9. McLafferty SL, GIS and health care, Annual Review of Public Health, 2003, 24(1):25-42

10. Tanser F and Wilkinson D, Spatial implications of the tuberculosis DOTS strategy in rural South Africa: a novel application of geographical information system and global positioning system technologies, Tropical Medicine E International Health, 1999, 4(10):634-638.

11. Kazembe LN, Appleton CC and Kleinschmidt I, Geographical disparities in core population coverage indicators for Roll Back Malaria in
Malawi, International Journal for Equity in Health, 2007, 6(1):5.

12. Lozano-Fuentes S et al., Use of Google Earth to strengthen public health capacity and facilitate management of vector-borne diseases in resource-poor environments, Bulletin of the World Health Organization, 2008, 86(9):718-725

13. Rosero-Bixby L, Spatial access to health care in Costa Rica and its equity: a GIS-based study, Social Science $\&$ Medicine, 2004, 58(7):12711284.

14. Entwisle B et al., A multilevel model of family planning availability and contraceptive use in rural Thailand, Demography, 1984, 21(4):559-574

15. Tsui AO and Ochoa LH, Service proximity as a determinant of contraceptive behaviour: evidence from cross-national studies of survey data, in: Phillips JF and Ross AJ, eds., Family Planning Programmes and Fertility, Oxford, England: Clarendon Press, 1992, pp. 222-256.

16. Steele F, Curtis SL and Choe M, The impact of family planning service provision on contraceptive-use dynamics in Morocco, Studies in Family Planning, 1999, 30(1):28-42.

17. Hong R, Montana L and Mishra V, Family planning services quality as a determinant of use of IUD in Egypt, BMC Health Services Research, 2006, 6(6):79.

18. Seiber EE and Bertrand JT, Access as a factor in differential contraceptive use between Mayans and ladinos in Guatemala, Health Policy and Planning, 2002, 17(2):167-177.

\section{Acknowledgments}

The baseline survey and creation of the Kinshasa Family Planning Coalition were supported by grant OPP101707 from the Bill and Melinda Gates Foundation. The follow-up survey was funded by grant 2013-38902 from The David and Lucile Packard Foundation. The authors thank Monica Kerrigan and Perri Sutton at the Bill and Melinda Gates Foundation, Tamara Kreinin and Sahlu Haile at The David and Lucile Packard Foundation, and Maria Carolina Herdoiza and Linnea Perry at Tulane University's School of Public Health and Tropical Medicine, for their contributions to and support of this work.

Author contact: bertrand@tulane.edu 